\title{
In Vitro Effect of Some Medicinal Plants on Leishmania major Strain MRHO/IR/7 5/ER
}

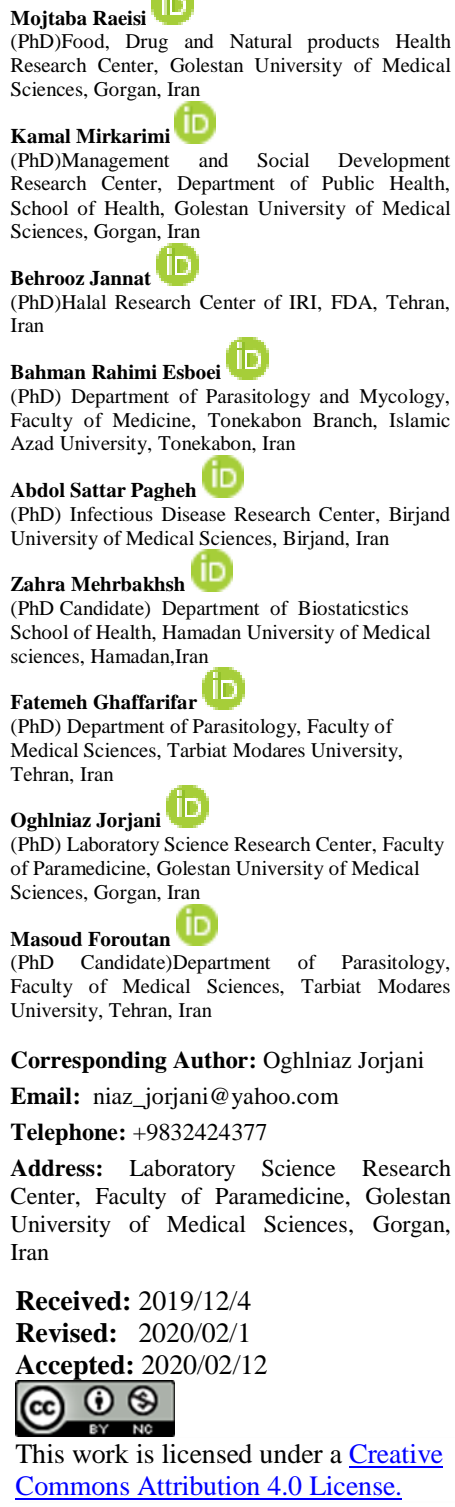

Received: 2019/12/4

Revised: 2020/02/

Accepted: 2020/02/12$$
\text { (c) (i) (3) }
$$

This work is licensed under a Creative Commons Attribution 4.0 License.

\begin{abstract}
Background and objectives: Leishmaniasis is a tropical disease caused by protozoan parasites from the genus Leishmania. In this study, we aimed at investigating the in vitro anti-leishmanial effect of essential oils of Rosmarinus officinalis, Mentha pulegium, Foeniculum vulgare, Lippia citriodora and Pelargonium graveolens.
\end{abstract}

Methods: The essential oils were prepared from freshly dried and powdered plants with steam-distilled water. Iranian strain of Leishmania promastigotes was cultured in RPMI medium and the inhibitory effects of different concentrations $(25,32,62.5,125,250,500$ and $1000 \mu \mathrm{g} / \mathrm{ml})$ of the essential oils were investigated at 24, 48 and 72 hours. The number of live parasites before and after treatment with the essential oils was counted by trypan blue $10 \%$ staining and using neobar lam.

Results: The essential oils significantly decreased the number of promastigotes in a dose-dependent manner $(\mathrm{P}<0.05)$. However, the inhibitory effects of $F$. vulgare and $R$. officinalis essential oils were more profound compared to other essential oils. Moreover, concentrations of 500 and $1000 \mu \mathrm{g} / \mathrm{ml}$ of these two essential oils exerted equal and more antileishmanial potency compared to glucantime, the first-line drug used for treatment of leishmaniasis.

Conclusion: Based on the results, it is recommended to evaluate the in vivo anti-leishmanial effects of the tested essential oils, particularly $F$. vulgare and $R$. officinalis.

Keywords: Rosmarinus officinalis, Mentha pulegium, Foeniculum vulgare, Lippia citriodora, Pelargonium graveolens, Leishmania 


\section{INTRODUCTION}

Leishmaniasis is a common, tropical disease caused by the protozoan Leishmania parasites, which mainly affects developing countries (1-3). Leishmaniasis is transmitted through the bite of Phlebotomus

papatasi and Lutzomyia sandflies (4). The disease is clinically classified into visceral, coetaneous (the most common) and mucocutaneous forms (5). Iran has the highest prevalence of coetaneous leishmaniasis and is ranked fourth in terms visceral leishmaniasis in the Middle East (6). Despite national and international investments against this disease, not only the disease has not been eradicated, but new hotspots have emerged in Iran (7).

Recent evidence suggests the emergence of resistance to pentavalent antimonials, which are commonly used for treatment of leishmaniasis (8). In addition, the high cost and lack of access to medications, particularly in rural areas, have further complicated the treatment of this disease. Therefore, researchers have been seeking suitable, effective alternatives to these drugs for treatment of leishmaniasis (9). Given the disadvantages of chemical medications including high-cost, adverse effects and risk of maladaptation, the use of medicinal plants has received a lot of attention (10). Some studies have reported moderate-strong antileishmanial activity of different plant essential oils (11-14).

Foeniculum vulgare is a herbaceous, aromatic plant from the parsley family, which looks like a dill with yellow umbelliferous flowers. The most active ingredients of this plant's essential oil include anethole, fenchone and phellandrene (15). Rose geranium (Pelargonium graveolens) is a slow-growing, perennial herb with long stems, rounded leaves and a rose-like flower (16). Lemon verbena (Lippia citriodora) is a shrub that growth 1.5 to 2 meter high and has simple leaves (diameter of 7 to $10 \mathrm{~cm}$ ) (17).

According to a previous study, the constituents of essential oil of Mentha pulegium include alpha-pinene, beta-pinene, limonene, 3octanol, paracymene, 3-octyl acetate, menton, isomenton, pulegone, isopulegone, pyrethrin, cis-pulegone oxide, trans-pulegone oxide, caryophyllene, lauric acid, myristic acid, palmitoleic acid, salisylaldehyde and hesperidine (11).

Rosmarinus officinalis $\mathrm{L}$. is a plant species that mainly originates from the Mediterranean region and Southern Asia. A limited number of studies have investigated the anti-parasitic effects of the above mentioned plants. Therefore, we aimed to evaluate the in vitro anti-leishmanial effects of essential oils of $R$. officinalis, $M$. pulegium, $F$. vulgare, $L$. Citriodora and $P$. graveolens.

\section{MATERIALS AND METHODS}

The essential oils were prepared by distillation with water. First, $100 \mathrm{~g}$ of $F$. vulgare (seeds), P. graveolens, L. citriodora, $M$. pulegium and $R$. officinalis leaves were powdered using a small electric mill and then distilled with $900 \mathrm{ml}$ water for two hours in a Clevenger type apparatus. The obtained essential oils were kept in colored glass containers at $4{ }^{\circ} \mathrm{C}$.

After isolation, the Iranian strain of Leishmania major (MRHO/IR/75/ER) was cultured in RPMI-1640 containing fetal calf serum $(30 \%)$ at the School of Public Health and Health Research, University of Tehran. Then, the culture suspension containing $20 \times 10^{6}$ parasites $/ \mathrm{ml}$ was treated with different concentrations (31.25, 62.5, 125, 250, 500 and $1000 \mu \mathrm{g} / \mathrm{ml}$ ) of the prepared essential oils. Inhibitory effects of the essential oils on the parasites were assessed after 24, 48 and 72 hours by MTT assay.

Since, $100 \mu l$ of culture medium containing $L$. major promastigotes (with $2 \times 10^{5}$ parasites per $\mathrm{ml}$ ) were added to wells of a 96 -well plate in duplicate. Subsequently, $10 \mu \mathrm{l}$ of different concentrations of the essential oils and glucantime (positive control) were added to the wells. In each plate, a well containing only the medium was considered as negative control. After 24, 48 and 72 hours of incubation, $10 \mu \mathrm{l}$ of MTT solution were added to each well. The plates were then incubated at $25 \pm 1{ }^{\circ} \mathrm{C}$ in the dark for 4 hours. After incubation, $100 \mu$ of dimethyl sulfoxide were added to each well to stop the reaction. Viability was assessed by reading absorbance at $570 \mathrm{~nm}$ using an ELISA reader. All experiments were repeated three times.

The mean absorbance was compared using two-way ANOVA. Data analysis was done using SPSS software (version 20) at significance of 0.05 . 


\section{RESULTS}

The major components of the essential oils are listed in table 1. As shown in figure 1, all tested essential oils could inhibit the growth of $L$. major promastigotes in a dose-dependent manner. The highest inhibitory effect was recorded at concentrations of 500 and 1000 $\mu \mathrm{g} / \mathrm{ml}$. In addition, $1000 \mu \mathrm{g} / \mathrm{ml}$ of $R$. officinalis and $F . v u$ lgare had significantly higher inhibitory effect on $L$. major promastigotes compared to glucantime (Figure 2). Based on the results, $1000 \mu \mathrm{g} / \mathrm{ml}$ of $P$. graveolens essential oil and $500 \mu \mathrm{g} / \mathrm{ml}$ of $R$. officinalis, $F$. vulgare and L. citriodora essential oils had no significant difference with glucantime in terms of anti-leishmanial effect.

Table 1. Major components of the essential oils using GC/MS analysis

\begin{tabular}{|c|c|c|c|}
\hline Essential oil & Major components & $\mathbf{K I}$ & Percent \\
\hline \multirow[t]{3}{*}{ Foeniculum vulgare } & E-anethole & 1303 & 67.06 \\
\hline & Fenchone & 1097 & 10.98 \\
\hline & $\alpha$-phellandrene & 1010 & 5.22 \\
\hline \multirow{3}{*}{ Pelargonium gra veolens } & Citronellol & 1236 & 31.33 \\
\hline & Geraniol & 1260 & 15.22 \\
\hline & Cytronellyl formate & 1279 & 8.07 \\
\hline \multirow[t]{2}{*}{ Aloysia citrodora } & Limonene & 1035 & 53.19 \\
\hline & $\alpha$-Terpincol & 1206 & 7.14 \\
\hline \multirow{3}{*}{ Rosemarinus officinalis } & Pinene $-\alpha$ & 934 & 32.44 \\
\hline & 1,8 Cineole & 1037 & 25.04 \\
\hline & Verbenone & 1220 & 4.15 \\
\hline \multirow[t]{2}{*}{ Mentha pulegium } & $\delta$-terpinene & 1052 & 32.16 \\
\hline & a traninanon & 1010 & 1001 \\
\hline
\end{tabular}

Figure 1. Inhibitory effects of the essential oils on promastigotes of $L$. major using the MTT assay

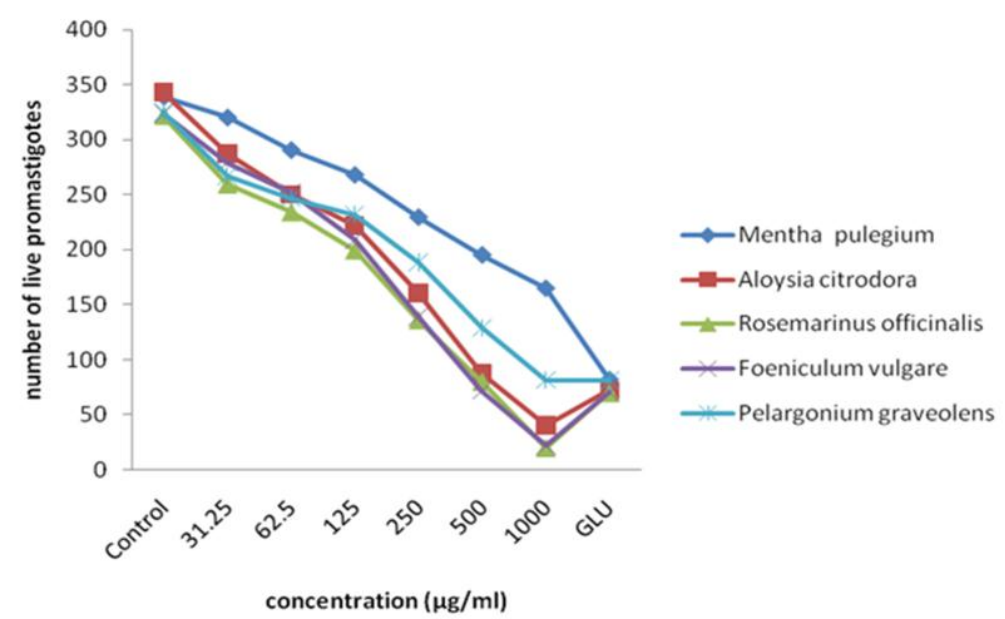

Figure 1. Inhibitory effects of the essential oils on promastigotes of $L$. major using the MTT assay 
Figure 2. Anti-leishmanial effect of the essential oils of $R$. officinalis (a), F. vulgare (b), P. graveolens (c), A. citrodora (d) and M. pulegium (e)

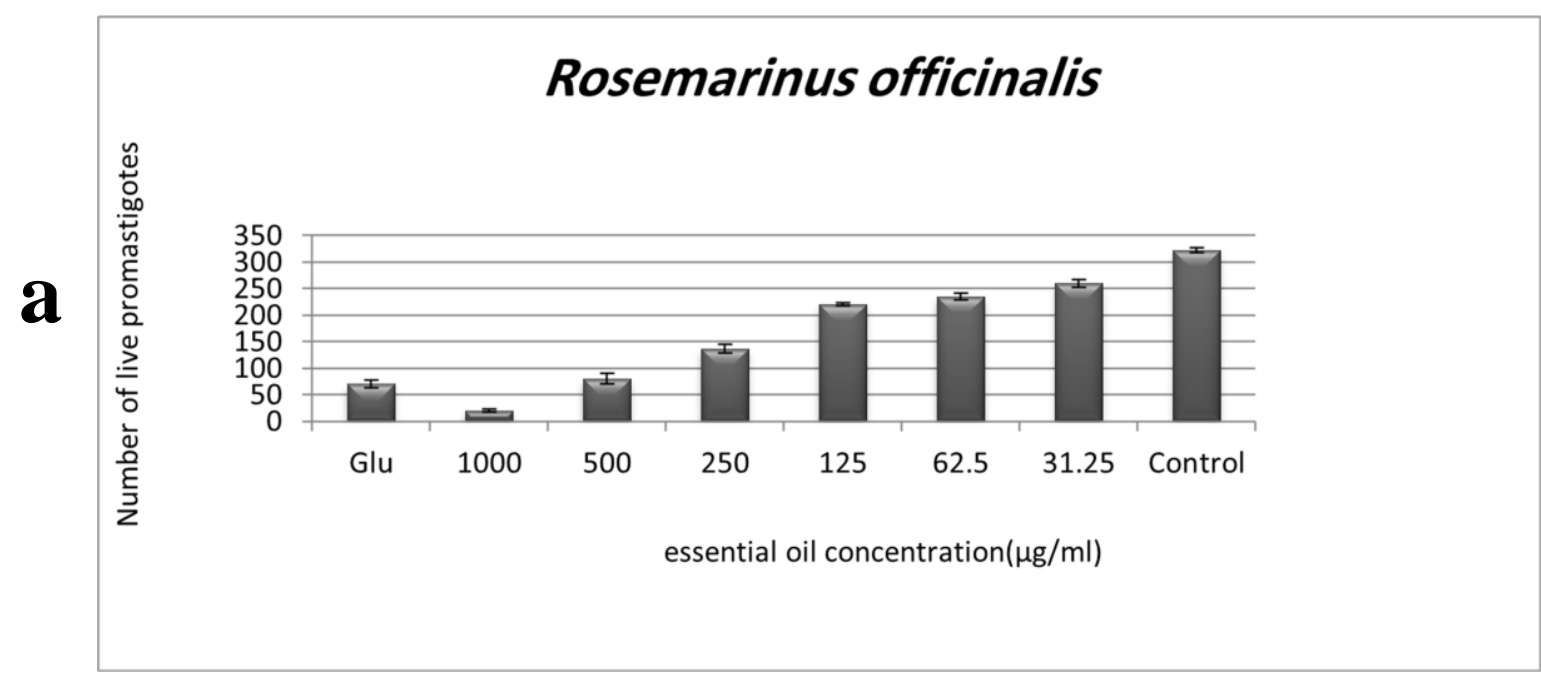

Foeniculum vulgare

b
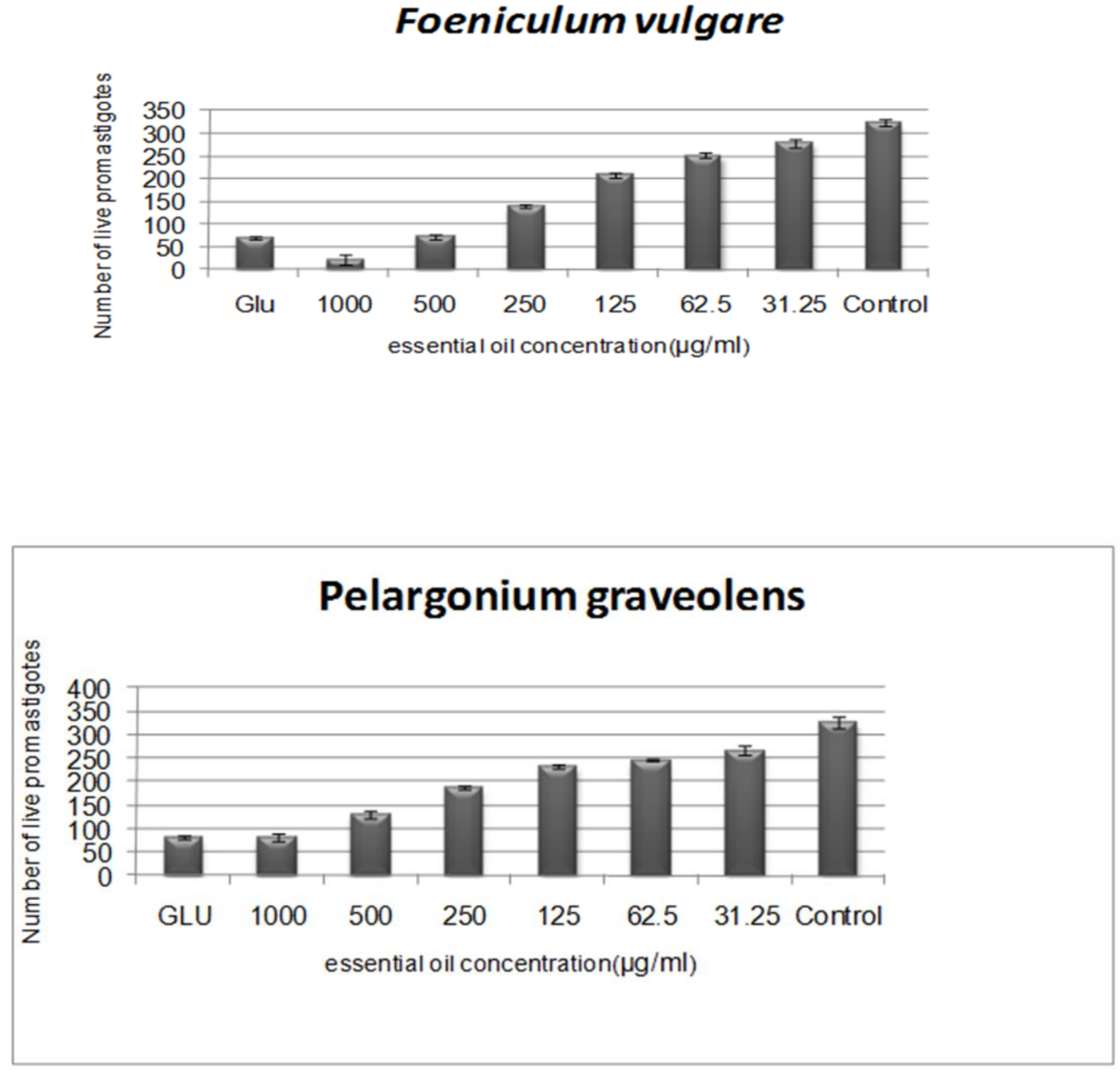


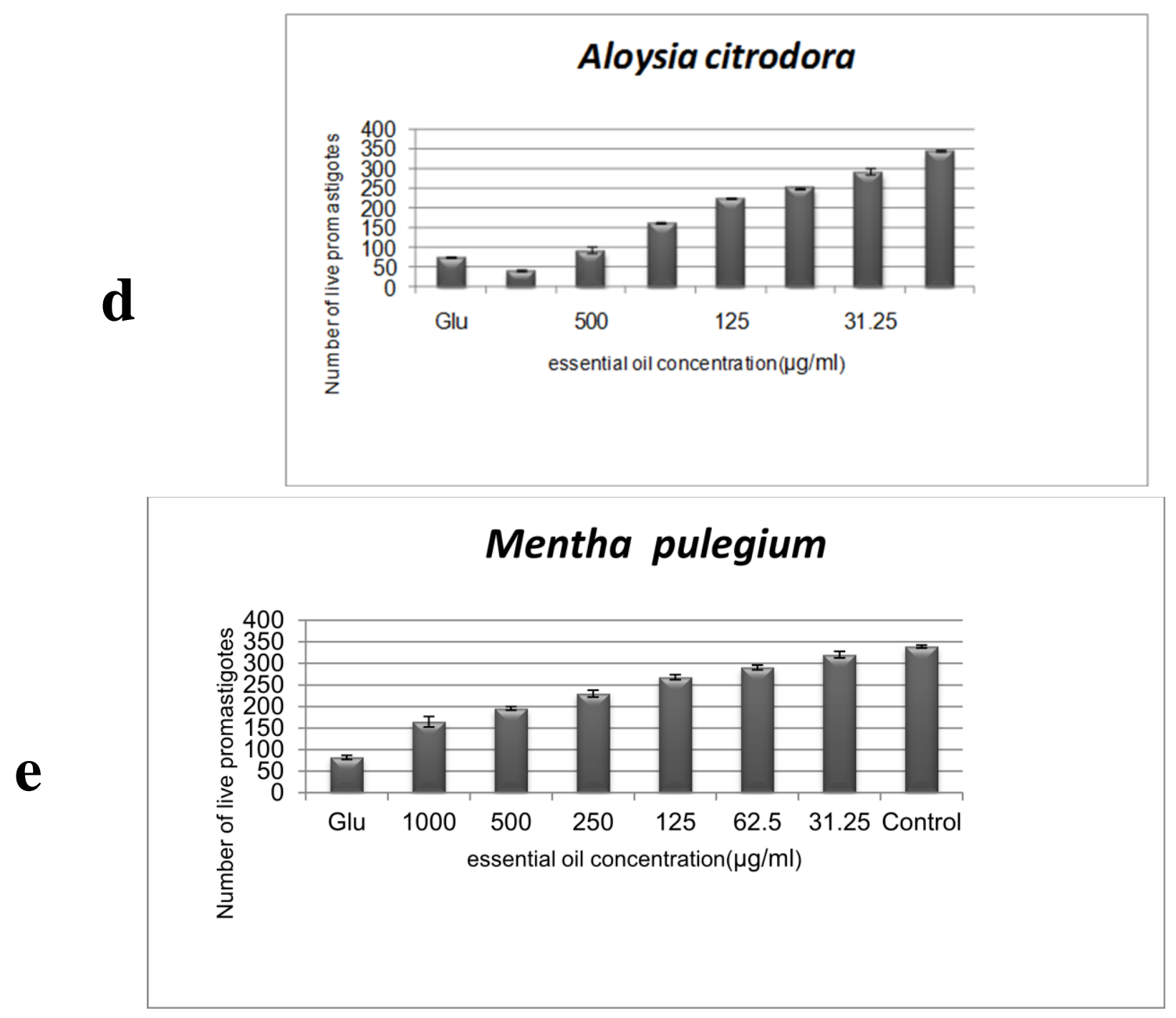

\section{DISCUSSION}

Several factors such as parasite, vector, host and environment may affect the pidemiology and symptoms of leishmaniasis (18). Given the lack of a vaccine and recent emergence of resistance to pentavalent antimonials, we investigated the anti-leishmanial effect of essential oils of $R$. officinalis, M. pulegium, $F$. vulgare, $L$. Citriodora and $P$. graveolens, which are native to Iran.

The main constituents of $F$. vulgare essential oil include E-anethole, fenchone and $\alpha$ phellandrene (19). The main components of $P$. graveolens essential oil were citronellol, geraniol and cytronellyl formate. The major components of $L$. citriodora essential oil were lemonene and $\alpha$-terpineol. Inconsistent with our findings, Hanna et al. identified 43 compounds in the essential oil of L. citriodora and reported that the most effective compounds are citral $(14.21 \%), \quad \beta$ caryophyllene (10.71\%), 1, 8-cineole $(9.1 \%)$ and citronellol (8.87\%). (20)The main components of $R$. officinalis essential oil were $\alpha$-pinene, 1,8 cineole and verbenone. Two other studies identified 20-25 compounds in $R$. officinalis essential oil and reported oxygenated mono-terpenes (camphor) and hydrocarbon terpenes (pinene) as the main constituents. The major components of $M$. pulegium essential oil were $\delta$-terpinene and $\alpha$ terpinene. In a study conducted by Gulluce et al., pyrethrin epoxide and pulegone were found as the major components of $M$. pulegium essential oil, which is inconsistent with our findings. The difference in chemical composition and antimicrobial activity of essential oils can be attributed to the differences in planting season, weather, geographic area, method and duration of essential oil extraction and tested microbial species (21-24).

Several studies have evaluated the effectiveness of Iranian medicinal plants against various diseases and infections such 
as leishmaniasis. Jedi et al. reported that the extract of Achilles spp. can have significant inhibitory effect on L. major in a timedependent manner (26). In a study by Jorjani et al., the essential oil of Eugenia caryophyllata and Cinnamomum zeylanicum significantly decreased the number of promastigotes compared with a control group (25).

In the present study, all tested essential oils exerted anti-leishmanial effects in a dosedependent manner. However, the essential oils of fennel and rosemary showed the highest inhibitory effects at concentrations of 500 and $1000 \mu \mathrm{g} / \mathrm{ml}$. In another study, Albakhit and Doudi reported the significant inhibitory effects ofmethanolic and aqueous extracts of Zizyphus spina-Christi against L. major (MHOM/IR/75/ER) promastigotes (26). In another study, the essential oil of $P$. angustifolium was introduced as a promising alternative for treatment of visceral leishmaniasis (14).

Ogeto et al. reported that the aqueous and methanolic extracts of Aloe secundiflora have the highest inhibitory effect on $L$. major promastigotes in vitro (27).

\section{REFERENCES}

1. Desjeux P. Leishmaniasis: current situation and new perspectives. Comparative immunology, microbiology and infectious diseases. 2004; 27(5): 305-18.

2. Murray HW, Berman JD, Davies CR, Saravia NG. Advances in leishmaniasis. The Lancet. 2005; 366(9496): 1561-77.

3. Desjeux P. The increase in risk factors for leishmaniasis worldwide. Trans R Soc Trop Med Hyg. 2001; 95(3): 239-43.

4. Wheeler RJ, Sunter JD, Gull K. Flagellar pocket restructuring through the Leishmania life cycle involves a discrete flagellum attachment zone. J Cell Sci. 2016; 129(4): 854-67. doi: 10.1242/jcs.183152.

5. Pagheh AS, Fakhar M, Mesgarian F, Rahimi-Esboei B, Badiee F. Incidence trend of rural cutaneous leishmaniasis in Gonbad-e-Qabus city,(Golestan, Iran) during 2009-2012. J Mazandaran Univ Med Sci. 2013; 23(104): 27-33.

6. Foroutan M, Khademvatan S, Majidiani H, Khalkhali H, Hedayati-Rad F, Khashaveh S, et al. Prevalence of Leishmania species in rodents: a systematic review and meta-analysis in Iran. Acta tropica. 2017; 172: 164-72.

7. Reed SG. Leishmaniasis vaccination: targeting the source of infection. Exp.Med. 2001;194: F7-F9.

8. Prates FV, Dourado ME, Silva SC, Schriefer A, Guimarães LH, Brito MdGO, et al. Fluconazole in the treatment of cutaneous Leishmaniasis caused by Leishmania braziliensis: a randomized controlled trial. Clinical Infectious Diseases. 2016: 662.
Plant essential oils can easily cross the cytoplasmic membrane and various cell layers due to their lipophilic structure and cause cell lysis. They may also interrupt with biosynthesis of lipids and proteins, increase the production of nitric oxide in damaged cells or stimulate de-polymerization of mitochondrial membrane, thereby causing cell death (28). The effect of essential oils on mitochondria of promastigotes and amastigotes have been demonstrated (29). De Medeiros et al. also reported that treatment with some plant extracts significantly alters the morphology of parasites in a dose-dependent manner (30).

\section{CONCLUSION}

All tested essential oils, particularly the essential oils of fennel and rosemary, are capable of eliminating $L$. major promastigotes with equal or higher potency than glucantime, the first-line drug for treating leishmaniasis.

\section{ACKNOWLEDGMENTS}

This research project was finically supported by the Golestan University of Medical Science, Gorgan, Iran.

\section{CONFLICT OF INTEREST}

The authors declare that there is no conflict of interest.

9. Moghaddas E, Khamesipour A, Mohebali M, Fata A. Iranian Native Plants on Treatment of Cutaneous Leishmaniosis: A Narrative Review. Iranian journal of parasitology. 2017; 12(3): 312-322.

10. Yakhchali M, Athari S, Hajimohammadi B, Raeisi M. Prevalence of Linguatula serrata in the ruminants slaughtered in Urmia slaughterhouse, Iran. Journal of Veterinary Research. 2009; 64(4): 329-332.

11. Bouyahya A, Et-Touys A, Bakri Y, Talbaui A, Fellah $\mathrm{H}$, Abrini J, et al. Chemical composition of Mentha pulegium and Rosmarinus officinalis essential oils and their antileishmanial, antibacterial and antioxidant activities. Microb pathog. 2017; 111: 41-9. doi: 10.1016/j.micpath.2017.08.015.

12. Manjili HK, Jafari H, Ramazani A, Davoudi N. Antileishmanial and toxicity activities of some selected Iranian medicinal plants. Parasitology research. 2012; 111(5): 2115-21.

13. Sozangar N, Jeddi F, Reaghi S, Khorrami S, Arzemani K. Abulkhalsa and yarrow plant effect on Leishmania major in vitro. JNKUMS. 2012; 4(3): 329333.

14. Bosquiroli LS, Demarque DP, Rizk YS, Cunha MC, Marques MCS, Maria de Fátima CM, et al. In vitro antiLeishmania infantum activity of essential oil from Piper angustifolium. Revista Brasileira de Farmacognosia. 2015; 25(2): 124-8. 
15. Diao W-R, Hu Q-P, Zhang H, Xu J-G. Chemical composition, antibacterial activity and mechanism of action of essential oil from seeds of fennel (Foeniculum vulgare Mill.). Food Control. 2014; 35(1): 109-16.

16. Motsa NM. Essential oil yield and composition of rose-scented geranium (Pelargonium sp.) as influenced by harvesting frequency and plant shoot age: University of Pretoria; 2006.

17. Carcas LP. Gastric cancer review. J Carcinog. 2014; 13: 14. doi: 10.4103/1477-3163.146506.

18. Evans TG, Teixeira MJ, McAuliffe IT, Barros Vasconcelos IdA, Vasconcelos AW, de Queiroz Sousa A, et al. Epidemiology of visceral leishmaniasis in northeast Brazil. Journal of Infectious Diseases. 1992; 166(5): 1124-32.

19. Miguel MG, Cruz C, Faleiro L, Simoes M, Figueiredo AC, Barroso JG, et al. Foeniculum vulgare essential oils: chemical composition, antioxidant and antimicrobial activities. Natural product communications. 2010; 5(2): 319-28.

20. Hanna A, El-Beltagi H, Nasr NF. Evaluation of Antioxidant and Antimicrobial Activity of Aloysia triphylla. Electronic J Environ Agric Food Chem. 2011; 10(11): 2689-2699.

21. Zaouali Y, Bouzaine T, Boussaid M. Essential oils composition in two Rosmarinus officinalis $L$. varieties and incidence for antimicrobial and antioxidant activities. Food Chem Toxicol. 2010; 48(11): 3144-3152.

22. Gulluce M, Sahin F, Sokmen M, Ozer H, Daferera D, Sokmen A, et al. Antimicrobial and antioxidant properties of the essential oils and methanol extract from Mentha longifolia L. ssp. longifolia. Food chemistry. 2007; 103(4): 1449-56.

23. Lemos MF, Lemos MF, Pacheco HP, Endringer DC, Scherer R. Seasonality modifies rosemary's composition and biological activity. Industerial crops and Products. 2015; 70: 41-47.

\section{How to Cite:}

Raeisi M, Mirkarimi K, Jannat B, Rahimi Esboei B, Pagheh AS, Mehrbakhsh Z, Ghaffarifar F, Jorjani O, Foroutan M. [In Vitro Effect of Some Medicinal Plants on Leishmania major Strain MRHO/IR/75/ER]. mljgoums. 2020; 14(4): 46-52. DOI:

$10.29252 / \mathrm{mlj} .14 .4 .46$
24. Gulluce M, Orhan F, Adiguzel A, Bal T, Guvenalp Z, Dermirezer LO. Determination of antimutagenic properties of apigenin-7-O-rutinoside, a flavonoid isolated from Mentha longifolia (L.) Huds. ssp. longifolia with yeast DEL assay. Toxicol Ind Health. 2013; 29(6): 534-40.

25. Jorjani O, Raeisi M, Hezarjaribi HZ, Soltani M, Soosaraei M. Studying the Chemical Composition in Vitro Activity of Cinnamomum zeylanicum and Eugenia caryophyllata Essential Oils on Leishmania major. Journal of Pharmaceutical Sciences and Research. 2017; 9(8): 1300-4.

26. Albakhit S, Doudi M. The evaluation of Methanolic and aqueous extracts effect of Zizyphus spina-Christi against Leishmania major (MHOM/IR/75/ER) promastigotes using MTT assay. Iran J Med Microbiol. 2016; 10(3): 54-60.

27. Ogeto T, Odhiambo R, Shivairo R, Muleke C, Osero $\mathrm{B}$, Anjili $\mathrm{C}$, et al. Antileishmanial activity of Aloe Secundiflora plant extracts against Leishmania Major. 2013; 13: 9-18.

28. Tariku Y, Hymete A, Hailu A, Rohloff J. In vitro evaluation of antileishmanial activity and toxicity of essential oils of Artemisia absinthium and Echinops kebericho. Chemistry \& biodiversity. 2011; 8(4): 614-23.

29. Ueda-Nakamura T, Mendonça-Filho RR, MorgadoDíaz JA, Maza PK, Dias Filho BP, Cortez DAG, et al. Antileishmanial activity of Eugenol-rich essential oil from Ocimum gratissimum. Parasitol Int. 2006; 55(2): 99-105.

30. De Medeiros MdGF, Da Silva AC, Citó AMdGL, Borges AR, De Lima SG, Lopes JAD, et al. In vitro antileishmanial activity and cytotoxicity of essential oil from Lippia sidoides Cham. Parasitol Int. 2011; 60(3): $237-41$. 